\title{
PENGARUH ABSORBEN TERHADAP KUALITAS FISIK MINYAK
}

\author{
Tri Ariani ${ }^{1,}$ Ovilia Putri Utami Gumay ${ }^{2}$ \\ Program Studi Pendidikan Fisika STKIP PGRI LUBUKLINGGAU ${ }^{1,2}$ \\ triariani.ta@gmail.com ${ }^{1}$
}

Submit, 27-11-2017 Accepted, 29-12-2017 Publish, 29-12-2017

\begin{abstract}
This study aims to determine the effect of aloe vera juice (absorbent) on the quality of cooking oil. Both types of oil are used to fry up to five times the frying pan to fry the tempeh weighing 1000 grams at a temperature of $180^{\circ} \mathrm{C}$. Furthermore, the oil that has been used up to five times the frying recycled again, by clarifying it using aloe vera juice. To determine the quality of oil used parameters of viscosity, specific gravity, refractive index, and free fatty acids. From the results of the research, it is found that the longer the number of fryers resulted in decreased oil quality. This can be seen from the increase in the number of parameters measured ie the viscosity, density, free fatty acid and decrease in the number of refractive index parameters. After the purification using aloe vera juice, the quality of oil is getting better. It is characterized by the decrease of viscosity, density and free fatty acid.
\end{abstract}

Keywords: Absorbent, Edible Oil

Abstrak: Penelitian ini bertujuan untuk mengetahui pengaruh sari lidah buaya (absorben) terhadap kualitas minyak goreng. Kedua jenis minyak digunakan untuk menggoreng hingga lima kali penggorengan untuk menggoreng tempe seberat 1000 gram pada suhu $180^{\circ} \mathrm{C}$. Selanjutnya minyak yang telah dipakai hingga lima kali penggorengan didaur ulang kembali, dengan cara menjernihkannya menggunakan sari lidah buaya. Untuk menentukan kualitas minyak digunakan parameter viskositas, berat jenis, indeks bias, dan asam lemak bebas. Dari hasil penelitian, diperoleh bahwa semakin lama jumlah penggorengan mengakibatkan kualitas minyak menurun. Hal ini terlihat dari kenaikan angka tiap parameter yang diukur yakni viskositas, massa jenis, asam lemak bebas dan penurunan angka parameter indeks bias. Setelah dilakukan penjernihan menggunakan sari lidah buaya, kualitas minyak semakin membaik. Hal ini ditandai dengan turunnya angka viskositas, massa jenis dan asam lemak bebas.

Kata Kunci : Absorben, Minyak Goreng

\section{PENDAHULUAN}

Minyak goreng adalah salah satu kebutuhan pokok masyarakat Indonesia pada umumnya dalam rangka memenuhi kebutuhan hidup sehari-hari. Minyak goreng yang kita konsumsi sehari-hari sangat erat kaitannya dengan kesehatan kita. Minimnya pengetahuan masyarakat tentang penggunaan minyak goreng yang baik menyebabkan masyarakat menggunakannya secara tidak tepat. Seringkali kita temukan penggunaan minyak goreng yang terlalu lama sehingga menyebabkan terjadinya perubahan warna, bau dan sifat-sifat fisika maupun kimia lainnya dari minyak goreng itu sendiri. Perubahan sifat fisika dan kimia dari minyak goreng akibat lamanya penggunaan ini tentu saja berpengaruh terhadap nilai gizi yang terkandung di dalam minyak goreng itu sendiri, dan secara langsung maupun tidak langsung mempengaruhi sistem kesehatan tubuh kita yang mengkonsumsi minyak goreng tersebut. Selama penggorengan perlu dilakukan pengamatan terhadap suhu penggorengan, pengambilan remah-remah bahan pangan goreng, penambahan minyak baru, dan selama periode tertentu minyak dibiarkan turun suhunya. Setiap hari dapat dilakukan penjernihan dengan menggunakan adsorben untuk mengurangi partikel-partikel bahan pangan dan sekaligus untuk mengurangi senyawa-senyawa yang mempercepat kerusakan minyak, sehingga umur pakai minyak dapat lebih panjang. Adsorben yang dapat digunakan yaitu sari lidah buaya (Febriansyah, 2008). 
Secara umum, lidah buaya dunia yang mempunyai potensi untuk dikembangkan sebagai tanaman obat dan bahan baku industri. Lidah buaya mengandung zat lignin yang dapat menembus dan meresap ke dalam kulit dan menahan hilangnya cairan dari permukaan kulit sehingga kulit tidak cepat kering dan tetap lembab. Tanaman lidah buaya juga memiliki khasiat sebagai penurun panas bagi anak-anak, nyeri lambung, sembelit, penyembuh luka bakar serta sebagai anti inflamasi, anti jamur, anti bakteri dan membantu proses regenerasi sel

Aloe vera atau lidah buaya mengandung semua jenis vitamin kecuali vitamin $\mathrm{D}$, mineral yang diperlukan untuk fungsi enzim, saponin yang berfungsi sebagai anti mikroba dan 20 dari 22 jenis asam amino. Dalam penggunaannya untuk perawatan kulit, Aloe vera dapat menghilangkan jerawat, melembabkan kulit, detoksifikasi kulit, penghapusan bekas luka dan tanda, mengurangi peradangan serta perbaikan dan peremajaan kulit. Dengan beragam manfaat yang terkandung dalam lidah buaya, pemanfaatannya kurang optimal oleh masyarakat yang hanya memanfaatkannya sebagai penyubur rambut. Lidah buaya merupakan tanaman yang mampu memperbaiki kualitas khemis maupun fisik minyak dan yang lebih baik dalam meningkatkan kualitas minyak.

Mekanisme adsorpsi dapat terjadi antara permukaan padat-padat, gas-padat, gas-cair, cair-cair, atau cair-padat. Mekanisme yang terjadi antara adsorben dengan minyak termasuk mekanisme cairpadat. Daya adsorpsi disebabkan karena adsorben memiliki pori dalam jumlah besar dan adsorpsi akan terjadi karena adanya perbedaan energi potensial antara adsorben dengan zat yang akan diserap. Penyerapan warna akan lebih efektif jika adsorben tersebut memiliki massa jenis yang rendah, merupakan satu dari 10 jenis tanaman di ukuran partikel halus, dan $\mathrm{pH}$ adsorben mendekati netral

\section{METODE PENELITIAN}

Penelitian ini dilaksanakan dengan menguji kualitas fisik minyak goreng bekas yang telah di gunakan sebanyak lima kali penggorengan dan aplikasi adsorben sari lidah buaya dalam pemurnian minyak goreng bekas pakai. Sampel yang digunakan dalam penelitian ini yaitu dua jenis minyak goreng yang berbeda merk. Kedua merk minyak ini dipakai hingga lima kali penggorengan untuk menggoreng tempe seberat 1000 gram dengan waktu 20 menit pada suhu $180^{\circ} \mathrm{C}$ setiap penggorengan, serta pengulangan yang dilakukan sebanyak tiga kali untuk masing-masing merk minyak. Jeda penggorengan yaitu setiap satu hari. Sampel minyak diambil langsung setelah proses pengggorengan, kemudian minyak didinginkan hingga dingin dan di lanjutkan dengan pengujian di laboratorium. Setelah dilakukan pengujian kualitas pada minyak goreng bekas, maka selanjutnya dilakukan penjernihan minyak goreng bekas menggunakan sari lidah buaya. Penjernihan minyak dilakukan dengan cara mencampurkan minyak bekas dengan sari lidah buaya dengan dan kemudian didiamkan selama 24 jam.

\section{Penentuan Viskositas Sampel}

Alat dan bahan yag digunakan dalam penentuan viskositas yaitu gelas ukur, bola kelereng, thermometer, gelang kawat / karet gelang, mistar gulung, stop watch, minyak goreng, neraca timbangan, dan mikrometer sekrup. dengan langkah kerja sebagai berikut:

1. Mengukur suhu fluida dengan termometer.

2 . Menghitung rapat massa bola kelereng dan rapat massa fluida

3. Tempatkan gelang kawat / karet gelang melingkar di tabung kira-kira $5 \mathrm{~cm}$ dari bawah 
permukaan zat cair dan sebuah karet gelang lagi di bagian bawah kira-

4 . kira5 $\mathrm{cm}$ dari dasar tabung $\mathrm{d}$

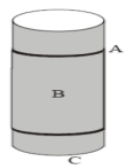

Gambar 1. Susunan Alat Eksperimen Secara Skematis
Keterangan
A : Gelang karet
B : Fluida kental
C : Tabung kaca

5 . Menjatuhkan kelereng ke dalam fluida dengan tanpa kecepatan awal.

6. Menghitung waktu yang diperlukan kelereng untuk menempuh jarak antara kedua gelang (d1) dengan menggunakan stop watch.

7 . Ukur jarak jatuh d (jarak antara kedua gelang karet)

8 . Hitung nilai

(Ganijanti,2002)

\section{Penentuan Berat Jenis Sampel}

Cara penentuan berat jenis dilakukan dengan menggunakan piknometer. Pertama, piknometer dibersihkan dan ditimbang untuk diketahui berat kosongnya. Piknometer kemudian diisi dengan minyak bersuhu. Pengisisan dilakukan sampai minyak dalam botol meluap dan tidak ada gelembung udara di dalamnya. Setelah ditutup, botol direndam dalam bak air yang bersuhu $25^{\circ} \mathrm{C}$ selama 30 menit. Botol kemudian diangkat dari bak dan dikeringkan dengan kertas pengisap. Kemudian ditimbang berat botol dan isinya. Selanjutnya, untuk mengetahui berat jenis sampel minyak, seperti halnya air, digunakan pula piknometer (Ketaren,2008).

Perhitungan Nilai Densitas dari sampel bahan bakar minyak nabati ini dihitung dengan menggunakan rumus:

Berat Jenis $=\frac{\text { (bobot piknometer dan minyak)-(bobot piknometer kosong }}{\text { wolume minyakpada } 25^{\circ} \mathrm{C}}$
(Ketaren, 2008)

\section{a. Penentuan Indeks Bias Sampel}

Cara mengukur mengukur indeks bias minyak diilustraskan pada gambar 2 dibawah ini.

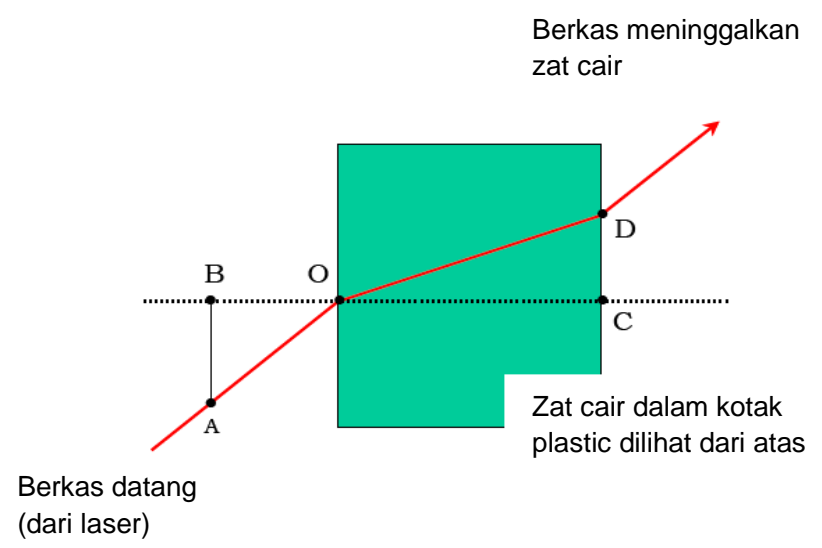

Gambar 2. Penentuan indeks bias

Sebuah kotak kaca transparan diisi zat cair tertentu yang akan diukur indeks biasnya. Berkas cahaya datang dengan arah tidak tegak lurus sisi kotak yang berisi zat cair. Ketika memasuki zat cair arah berkas dibelokkan, dan ketika keluar dari zat cair pada sisi seberang arah cahaya dibelokkan kembali. Peristiwa pembiasan pada bidang batas antara dua medium memenuhi hukum Snell

$n_{1} \sin \theta=n_{2} \sin \theta$

dengan

$\mathrm{n}_{1}=$ indeks bias medium tempat cahaya datang

$\theta_{1}=$ sudut datang

$\mathrm{n}_{2}=$ indeks bias medium tempat cahaya bias

$\theta_{2}=$ sudut bias

Berdasarkan Gambar. 3 kita tidak perlu mengukur sudut secara langsung. Nilai sinus sudut datang dan sudut bias dapat dihitung berdasarkan pengukuran lokasi 
jatuhnya sinar datang dan sinar bias. Maka indeks bias zat cair dapat ditentukan dari rumus

$$
n=\frac{\sin i}{\sin r}
$$

Keterangan :

1) $n=$ indeks bias mutlak

2) $i=$ sudut datang

3) $r=$ sudut bias

(Sutiah K, 2008)

\section{Penentuan Asam Lemak Bebas}

Cara menentukan asam lemak bebas yaitu dengan menggunakan metode titrasi. Adapun langkah-langkahnya seperti di bawah ini:

1. Dimasukkan 2, 5 gram minyak ke dalam erlenmeyer, ditambahkan $5 \mathrm{ml}$ alkohol lalu dipanaskan di atas hotplate sampai campuran homogen

2. Campuran didinginkan dan ditambahkan 2 tetes indikator phenolptalein

3. Campuran dititrasi dengan $\mathrm{NaOH} 0,1 \mathrm{~N}$, titrasi diakhiri dengan terbentuknya warna merah jambu dan warnanya tidak hilang selama 30 detik

4. Dihitung FFA dengan persamaan:

$$
\% \text { FFA } \frac{\text { mL NaOH x N NaOH x BM Asam Lemak }}{\text { Berat contoh x } 1000} 100 \%
$$

(4)

(Ketaren, 2008)

Data yang diperoleh selanjutnya dianalisis menggunkan uji ANAVA dua jalur untuk melihat apakah ada pengaruh yang signifikan dari jenis minyak dan pemakaian berulang. Untuk melihat perbedaan pada masing pemakaian dilakukan uji lanjut posthoc dengan uji tukey HSD dan uji Duncan

\section{HASIL DAN PEMBAHASAN}

Mutu minyak goreng dapat ditingkatkan kembali dengan menginteraksikannya dengan absorben. Absorben yang digunakan dalam penelitian ini adalah sari lidah buaya. Penjernihan minyak dilakukan dengan cara mencampurkan minyak bekas dengan sari lidah buaya, dan kemudian didiamkan selama 24 jam. Setelah dilakukan penjernihan, selanjutnya di uji kembali kualitas nya, dengan parameter viskositas, berat jenis, indeks bias, dan kadar asam lemak bebas. Berikut disajikan tabel kualitas minyak goreng setelah penjernihan dengan sari lidah buaya:

Tabel 1. Perbandingan kualitas minyak baru, bekas dan

\begin{tabular}{|c|c|c|c|c|}
\hline \multirow{2}{*}{$\begin{array}{l}\text { Parame } \\
\text { ter yang } \\
\text { di ukur }\end{array}$} & \multirow{2}{*}{$\begin{array}{c}\text { Jenis } \\
\text { Miny } \\
\text { ak }\end{array}$} & \multicolumn{3}{|c|}{ Minyak } \\
\hline & & Baru & Bekas & $\begin{array}{c}\text { Hasil } \\
\text { Penjer } \\
\text { nihan }\end{array}$ \\
\hline \multirow{2}{*}{$\begin{array}{c}\text { Viskosit } \\
\text { as } \\
\text { (cP) }\end{array}$} & A & $\begin{array}{l}86,11 \pm \\
0,37_{\text {(a) }}\end{array}$ & $\begin{array}{l}98,59 \pm \\
0,36_{(b)}\end{array}$ & $\begin{array}{l}86,94 \pm \\
0,41_{\text {(a) }}\end{array}$ \\
\hline & B & $\begin{array}{l}93,09 \pm \\
0,01_{(\mathbf{a})}\end{array}$ & $\begin{array}{c}105,07 \\
\pm 0,03_{(\mathbf{b})}\end{array}$ & $\begin{array}{c}94,11 \pm \\
0,002 \\
\text { (ab) }\end{array}$ \\
\hline \multirow{2}{*}{$\begin{array}{c}\text { Berat } \\
\text { Jenis } \\
\left(\mathrm{mg} / \mathrm{cm}^{3}\right. \\
)\end{array}$} & A & $\begin{array}{c}0,67 \pm 0 \\
002_{(\mathbf{a})}\end{array}$ & $\begin{array}{l}0,79 \pm 0 \\
0001_{(b)}\end{array}$ & $\begin{array}{l}0,81 \pm 0 \\
0008_{(\mathbf{a b}}\end{array}$ \\
\hline & B & $\begin{array}{c}0,78 \pm 0 \\
001_{(\mathbf{a})}\end{array}$ & $\begin{array}{l}0,82 \pm 0 \\
0009_{(\mathbf{b})}\end{array}$ & $\begin{array}{c}0,83 \pm 0 \\
00005 \\
\text { (ab) }\end{array}$ \\
\hline \multirow{2}{*}{$\begin{array}{c}\text { Indeks } \\
\text { Bias }\end{array}$} & A & $\begin{array}{c}1,44 \pm 0 \\
004_{(\mathbf{a})}\end{array}$ & $\begin{array}{c}1,62 \pm 0 \\
004_{(\mathbf{b})}\end{array}$ & $\begin{array}{c}1,47 \pm 0 \\
004_{(\mathbf{a})}\end{array}$ \\
\hline & B & $\begin{array}{c}1,46 \pm \\
0,004_{\text {(a) }}\end{array}$ & $\begin{array}{c}1,64 \pm 0 \\
008_{(\mathbf{b})}\end{array}$ & $\begin{array}{c}1,50 \pm 0 \\
004\left(_{a}\right)\end{array}$ \\
\hline \multirow{2}{*}{$\begin{array}{c}\text { Asam } \\
\text { lemak } \\
\text { bebas(\% } \\
)\end{array}$} & A & $\begin{array}{c}0,06 \\
\pm 0,004 . \\
\text { (a) }\end{array}$ & $\begin{array}{c}0,40 \\
(\underline{4}), 004 \\
\text { (b) }\end{array}$ & $\begin{array}{c}0,15 \\
\pm 0,004( \\
\text { ab) }\end{array}$ \\
\hline & B & $\begin{array}{c}0,11 \pm 0 \\
, \mathbf{0 0 8}(\mathbf{a})\end{array}$ & $\begin{array}{c}0,86 \\
\pm 0,02 \\
\text { (b) }\end{array}$ & $\begin{array}{c}0,33 \pm 0 \\
02_{(\mathbf{a b})}\end{array}$ \\
\hline
\end{tabular}
hasil penjernihan

Keterangan : pada baris yang sama huruf di belakang angka menunjukkan hasil beda nyata dengan uji tukes HSD dan Duncan pada taraf kepercayaan $95 \%$

Keterangan : pada baris yang sama huruf di belakang angka menunjukkan hasil beda nyata dengan uji tukes HSD dan Duncan pada taraf kepercayaan $95 \%$

Berdasarkan data yang ada pada tabel $1 \mathrm{di}$ atas, terlihat bahwa terdapat perbedaan nyata antara minyak goreng baru dan minyak goreng bekas. Terjadi penurunan kualitas minyak setelah minyak 
dipakai hingga lima kali pemakaian. Penurunan kualitas minyak ini terlihat dari bertambahnya nilai viskositas, berat jenis, indeks bias dan asam lemak bebas. Setelah diukur kualitas minyak baru dan minyak bekas, selanjutnya digunakan sari lidah buaya untuk penjernihan minyak bekas. Dari tabel 1 terlihat aplikasi absorben sari lidah buaya belum berpengaruh terhadap berat jenis minyak. Setelah penjernihan nilai berat jenis semakin besar. Berbeda dengan viskositas, indeks bias, dan kadar asam lemak bebasnya yang mengalami penurunan setelah dijernihkan dengan sari lidah buaya. Dari data di atas jika dibandingkan antara kedua merk minyak tersebut, minyak goreng A cenderung lebih berkualitas dari pada minyak goreng $\mathrm{B}$. Hal ini terlihat dari rata-rata hasil pengukuran tiap parameter kualitas minyak. Rata-rata hasil pengukuran tiap parameter kualitas pada minyak goreng $\mathrm{B}$ cenderung lebih tinggi dari rata-rata hasil pengukuran tiap parameter pada minyak goreng $\mathrm{B}$, begitu juga dengan volume minyak yang hilang. Volume minyak goreng B yang hilang untuk setiap kali pemakaian juga cenderung lebih besar dari pada minyak goreng $\mathrm{B}$. Perbedaan kualitas kedua merk minyak ini dapat disebabkan karena minyak goreng $\mathrm{A}$ disaring dengan dua kali penyaringan, sedangkan minyak goreng B proses penyaringan hanya satu kali. Sehingga dari warnanya berbeda dengan minyak goreng A yang lebih jernih dibanding minyak goreng B.

Adanya proses penjernihan ini bertujuan untuk memisahkan fraksi-fraksi berat dalam minyak sehingga diperoleh minyak bebas bumbu dan warna gelap minyak menjadi coklat. Hal ini dikarenakan kotoran yang terdapat dalam minyak yang telah dipakai sebanyak lima kali sebagian terserap oleh daging Lidah buaya. Lidah buaya berperan sebagai absorben, sehingga dapat memberikan pengaruh positif terhadap jelantah. Daya serap lidah buaya disebabkan adanya poripori mikro yang sangat besar jumlahnya, sehingga menimbulkan gejala kapiler yang mengakibatkan adanya daya serap. Ketaren (2008) menambahkan bahwa daya adsorsi disebabkan karena adsorben memiliki pori dalam jumlah besar dan adsorpsi akan terjadi karena adanya perbedaan energi potensial antara adsorben dengan zat yang akan diserap.

Secara umum adsorbsi adalah proses pemisahan komponen tertentu dari satu fasa fluida (larutan) ke permukaan zat padat yang menyerap (adsroben). Pemisahan terjadi karena perbedaan bobot molekul atau porositas, menyebabkan sebagian molekul terikat lebih kuat pada permukaan dari pada molekul lainnya. Adapun syarat-syarat untuk berjalannya suatu proses adsorbsi, yaitu terdapat : 1. Zat yang mengadsorbsi (adsorben), 2. Zat yang teradsorbsi(adsorbat), 3. Waktu pengocokan sampai adsorbs berjalan seimbang. Adsorbsi dapat digolongkan dalam dua jenis, yaitu adsorbsi secara kimia dan secara fisika. Adsorbsi secara kimia (kemisorbsi) adalah adsorbs yang terjadi karena adanya gaya-gaya kimia dan diikuti oleh reaksi kimia. Adsorbsi jenis ini mengakibatkan terbentuknya ikatan secara kimia, sehingga diikuti dengan reaksi berupa senyawa baru. Pada kemisorbsi permukaan padatan sangat kuat mengikat molekul gas atau cairan sehingga sukar untuk dilepas kembali, sehingga proses kemisorbsi sangat sedikit. Adsorbsi fisika (fisiosorbsi) adalah adsorbsi yang terjadi karena adanya gaya-gaya fisika. Adsorbsi ini dicirikan adanya kalor adsorbs yang kecil (10 kkal/mol). Molekulmolekul yang diadsorbsi secara fisik tidak terikat secara kuat pada permukaan dan biasanya terjadi pada proses reversible yang cepat, sehingga mudah diganti dengan molekul lain 


\section{SIMPULAN}

Kualitas minyak goreng A dan B setelah dijernihkan dengan sari lidah buaya mengalami kenaikan. Perubahan viskositas, indeks bias dan asam lemak bebas telah sesuai dengan SNI 01-3741-2002 standar mutu minyak goreng, sehingga minyak layak untuk di konsumsi

\section{DAFTAR PUSTAKA}

Febriansyah, Reza. (2008). Pengaruh Penggunaan Berulang Dan Aplikasi Adsorben Terhadap Kualitas Minyak Dan Tingkat Penyerapan Minyak Pada Kacang Salut. Tesis. Bogor: Institut Pertanian Bogor

Ganijanti. (2002). Seri Fisika Dasar Mekanika. Jakarta: Salemba Teknika

K, Sutiah, Sofjan Firdausi dan Wahyu Setia Budi. (2008). Studi Kualitas Minyak Goreng Dengan Parameter Viskositas Dan Indeks Bias. 11(5), 53-58

Ketaren, S. (2008). Pengantar Minyak dan Lemak Pangan, UI Press, Jakarta. 